\title{
FIXED POINT THEOREMS FOR COMPATIBLE MAPPINGS WITH APPLICATIONS TO THE SOLUTIONS OF FUNCTIONAL EQUATIONS ARISING IN DYNAMIC PROGRAMMINGS
}

\section{NAN-JING HUANG}

Department of Mathematics

Sichuan University

Chengdu, Sichuan 610064

P.R CHINA

\section{BYUNG SOO LEE}

Department of Mathematics Kyungsung University Pusan 608-736

KOREA

\section{MEE KWANG KANG}

Department of Mathematics

Dongeui University

Pusan 614-714

KOREA

(Received October 4, 1995 and in revised form February 21, 1996)

ABSTRACT. Some common fixed point theorems for compatible mappings are shown As an application, the existence and uniqueness of common solutions for a class of functional equations arising in dynamic programmings are discussed.

KEY WORDS AND PHRASES: Common fixed point, compatible mapping, dynamic programming 1991 AMS SUBJECT CLASSIFICATION CODES: 54H25, 47H10

\section{INTRODUCTION}

In [1] the concept of compatible mappings was introduced as a generalization of commuting mappings and further investigation was given in [2-9]

The purpose of this paper is to prove some common fixed point theorems for compatible mappings, which generalized some recent results of $[4,10-13]$ As an application, we use the results presented to study the existence and uniqueness problem of a common solution for a class of functional equations arising in dynamic programmings, which generalized the corresponding results of $[14,15]$.

\section{FIXED POINT THEOREMS}

DEFINITION 2.1. Self mappings $A$ and $S$ of a metric space $(X, d)$ are called compatible, if $\lim _{n} d\left(A S x_{n}, S A x_{n}\right)=0$ whenever $\left\{x_{n}\right\}$ is a sequence in $X$ such that $\lim _{n} A x_{n}=\lim _{n} S x_{n}=t$ for some $t$ in $X$

It is clear that commuting mappings and weakly commuting mappings are all compatible mappings, but the converse is false (see $[1,4])$.

LEMMA $2.2[1,4]$ If $A$ and $S$ are compatible self mappings of a metric space $(X, d)$ and $\lim _{n} S x_{n}=\lim _{n} A x_{n}=t$ for some $t$ in $X$, then $\lim _{n} A S x_{n}=S t$ if $S$ is continuous.

The following theorem can be obtained from Theorem 8 in [16].

THEOREM 2.3. Let $(X, d)$ be a complete metric space and $A, B, S$ and $T$ are self mappings of $X$. Suppose that $S$ and $T$ are continuous, $A(X) \subset T(X), B(X) \subset S(X)$, and that $A, S$ and $B, T$ are compatible and satisfy the following condition:

$$
\begin{array}{r}
d(A x, B y) \leq \Phi(\max \{d(S x, T y), d(S x, A x), d(T y, B y), \\
\left.\left.\frac{1}{2}[d(S x, B y)+d(T y, A x)]\right\}\right), \forall x, y \in X,
\end{array}
$$

where $\Phi:[0, \infty) \rightarrow[0, \infty)$ is nondecreasing, upper semicontinuous and $\Phi(t)<t$ for all $t>0$ 
Then $A, B, S$ and $T$ have a unique common fixed point in $X$

We merely state the proof for convenience

PROOF. Since $A(X) \subset T(X)$ and $B(X) \subset S(X)$, we can choose a sequence $\left\{x_{n}\right\}$ in $X$ such that $S x_{2 n}=B x_{2 n-1}$ and $T x_{2 n-1}=A x_{2 n-2}$ for all $n$ in the set $\mathbb{N}$ of all positive integers Let

$$
\left.\begin{array}{l}
y_{2 n-1}=T x_{2 n-1}=A x_{2 n-2} \\
y_{2 n}=S x_{2 n}=B x_{2 n-1}
\end{array}\right\}(n \in \mathbb{N})
$$

As in [10], we can prove that $\left\{y_{n}\right\}$ is a Cauchy sequence in $X$ Letting $y_{n} \rightarrow y_{*} \in X(n \rightarrow \infty)$, we know that $\left\{y_{2 n}\right\}$ and $\left\{y_{2 n-1}\right\}$ converge to $y_{*}$ too.

Since $A$ and $S, B$ and $T$ are both compatible, it follows from the continuity of $S$ and $T,(2.2)$ and Lemma 2.2 that

$$
T y_{2 n-1} \rightarrow T y_{*}, \quad B y_{2 n-1} \rightarrow T y_{*}, \quad S y_{2 n} \rightarrow S y_{*}, \quad A y_{2 n} \rightarrow S y_{*}
$$

By (2.1) and (2.2) we have

$$
\begin{aligned}
d\left(A y_{2 n}, B y_{2 n-1}\right) \leq & \Phi\left(\operatorname { m a x } \left\{d\left(S y_{2 n}, T y_{2 n-1}\right), d\left(S y_{2 n}, A y_{2 n}\right),\right.\right. \\
& \left.\left.d\left(T y_{2 n-1}, B y_{2 n-1}\right), \frac{1}{2}\left[d\left(S y_{2 n}, B y_{2 n-1}\right)+d\left(T y_{2 n-1}, A y_{2 n}\right)\right]\right\}\right) .
\end{aligned}
$$

By the upper semicontinuity of $\Phi(t)$ and (2.3) we have

$$
\begin{aligned}
d\left(S y_{*}, T y_{*}\right) & \leq \Phi\left(\max \left\{d\left(S y_{*}, T y_{*}\right), 0,0, d\left(S y_{*}, T y_{*}\right)\right\}\right) \\
& =\Phi\left(d\left(S y_{*}, T y_{*}\right)\right) .
\end{aligned}
$$

This implies that $S y_{*}=T y_{*}$

Similarly, from (2.1), (2.2) and (2.3) we can obtain

$$
S y_{*}=B y_{*}, \quad T y_{*}=A y_{*} .
$$

Hence we have

$$
A y_{*}=B y_{*}=S y_{*}=T y_{*}
$$

From (2.1) and (2.2) we have

$$
\begin{aligned}
d\left(A x_{2 n}, B y_{*}\right) \leq & \Phi\left(\operatorname { m a x } \left\{d\left(S x_{2 n}, T y_{*}\right), d\left(S x_{2 n}, A x_{2 n}\right),\right.\right. \\
& \left.\left.d\left(T y_{*}, B y_{*}\right), \frac{1}{2}\left[d\left(S x_{2 n}, B y_{*}\right)+d\left(T y_{*}, A x_{2 n}\right)\right]\right\}\right),
\end{aligned}
$$

and then

$$
d\left(y_{*}, B y_{*}\right) \leq \Phi\left(d\left(y_{*}, B y_{*}\right)\right)
$$

Hence we have $y_{*}=B y_{*}=A y_{*}=S y_{*}=T y_{*}$

The uniqueness is obvious. This completes the proof.

DEFINITION 2.4. A metric space $(X, d)$ is (metrical) convex, if for each $x, y \in X$ with $x \neq y$, there exists a $z \in X, x \neq z \neq y$, such that

$$
d(x, z)+d(z, y)=d(x, y) .
$$

LEMMA 2.5 [17]. Let $K$ be a closed subset of a complete convex metric space $X$. If $x \in K$ and $y \notin K$, then there exists a point $z \in \partial K$ such that

$$
d(x, z)+d(z, y)=d(x, y) .
$$

DEFINITION 2.6. Let $(X, d)$ be a metric space, $K \subset X$ and $A, S: K \rightarrow X$. The pair of mappings $A$ and $S$ is called compatible, if $\lim _{n} d\left(A S x_{n}, S A x_{n}\right)=0$ whenever $\left\{x_{n}\right\}$ is a sequence in $K$ such that $A x_{n}, S x_{n} \in K$ and $\lim _{n} A x_{n}=\lim _{n} S x_{n}=t \in K$ 
LEMMA 2.7. Let $(X, d)$ be a metric space, $K \subset X$ and $A, S: K \rightarrow X \quad$ If $A$ and $S$ are compatible mappings, $A x_{n}, S x_{n} \in K$ and $\lim _{n} A x_{n}=\lim _{n} S x_{n}=t$ for some $t \in K$, then $\lim _{n} A S x_{n}=S t$ if $S$ is continuous.

PROOF. It is obvious from Definition 26

THEOREM 2.8. Let $(X, d)$ be a complete convex metric space and $K$ a nonempty closed subset of $X$ Suppose that $S$ and $T$ are continuous mappings from $X$ into $X$ with $\partial K \subset S(K) \cap T(K)$ and that $A, B: K \rightarrow X$ are continuous mappings with $A(K) \cap K \subset S(K), B(K) \cap K \subset T(K) \quad$ Suppose further that the pairs of mappings $A, T$ and $B, S$ are compatible and satisfying

$$
d(A x, B y) \leq \Phi(d(T x, S y)), \forall x, y \in K,
$$

where $\Phi:[0, \infty) \rightarrow[0, \infty)$ is nondecreasing upper semi-continuous and $\sum \Phi^{n}(t)<\infty$ for all $t \geq 0$

If for $x \in K, T x \in \partial K$ implies $A x, B x \in K$ and $S x \in \partial K$ implies $A x, B x \in K$, then there exists a $z \in K$ such that

$$
z=T z=S z=A z=B z .
$$

If $T v=S v=A v=B v$, then $T z=T v$

PROOF. Let $p \in \partial K$. Using Lemma 25 and the proof of [11] we can choose two sequences $\left\{p_{n}\right\}_{n \in \mathbf{N}}$ and $\left\{p_{n}^{\prime}\right\}_{n \in \mathbf{N}}$ such that for any $n \in \mathbb{N}, p_{n} \in K, p_{2 n-1}^{\prime}=A p_{2 n}, p_{2 n}^{\prime}=B p_{2 n-1}$ and the following implications hold

$$
\text { If } p_{2 n}^{\prime} \in K \text {, then } p_{2 n}^{\prime}=T p_{2 n} \text {, if } p_{2 n}^{\prime} \notin K \text {, then } T p_{2 n} \in \partial K \text { and }
$$

$$
d\left(S p_{2 n-1}, T p_{2 n}\right)+d\left(T p_{2 n}, B p_{2 n-1}\right)=d\left(S p_{2 n-1}, B p_{2 n-1}\right)
$$

$$
\text { If } p_{2 n+1}^{\prime} \in K \text {, then } p_{2 n+1}^{\prime}=S p_{2 n+1} \text {, if } p_{2 n+1}^{\prime} \notin K \text {, then } S p_{2 n+1} \in \partial K \text { and }
$$

$$
d\left(T p_{2 n}, S p_{2 n+1}\right)+d\left(S p_{2 n+1}, A p_{2 n}\right)=d\left(T p_{2 n}, A p_{2 n}\right)
$$

Further, as in [3] we can prove that

$$
\left.\begin{array}{l}
d\left(T p_{2 n}, S p_{2 n+1}\right) \leq \Phi^{n-1}(r) \\
d\left(S p_{2 n+1}, T p_{2 n+2}\right) \leq \Phi^{n}(r)
\end{array}\right\} \quad(n \in \mathbb{N})
$$

where $r=\max \left\{d\left(T p_{2}, S p_{3}\right), d\left(T p_{2}, S p_{1}\right)\right\}$

This implies that for any $n \in \mathbb{N}$,

$$
d\left(T p_{2 n}, T p_{2 n+2}\right) \leq \Phi^{n-1}(r)+\Phi^{n}(r) .
$$

Hence the sequence $\left\{T p_{2 n}\right\}_{n \in \mathbf{N}}$ is a Cauchy sequence. Since $X$ is complete and $K$ is closed, it follows that there exists a $z \in K$ such that $z=\lim _{n} T p_{2 n}$ From (26) we have

$$
z=\lim _{n} T p_{2 n}=\lim _{n} S p_{2 n+1} \text {. }
$$

Now we prove that $z=T z=S z=A z=B z$ It is obvious that there exists a sequence $\left\{n_{k}\right\} \subset \mathbb{N}$ such that $T p_{2 n_{k}}=B p_{2 n_{k}-1}$, or $S p_{2 n_{k}-1}=A p_{2 n_{k}-2}, \forall k \in \mathbb{N}$. Without loss of generality, we can suppose that $T p_{2 n_{k}}=B p_{2 n_{k}-1}, \forall k \in \mathbb{N}$ From (2.5) we have

$$
\begin{aligned}
d\left(S T p_{2 n_{k}}, A z\right) & \leq d\left(S B p_{2 n_{k}-1}, B S p_{2 n_{k}-1}\right)+d\left(B S p_{2 n_{k}-1}, A z\right) \\
& \leq d\left(S B p_{2 n_{k}-1}, B S p_{2 n_{k}-1}\right)+\Phi\left(d\left(S S p_{2 n_{k}-1}, T z\right)\right) .
\end{aligned}
$$

Since $B, S$ are compatible and $S$ is continuous, we have

$$
d(S z, A z) \leq \Phi(d(S z, T z)) .
$$

From (2.5) we have 


$$
\begin{aligned}
d\left(A p_{2 n_{k}}, T p_{2 n_{k}}\right) & =d\left(A p_{2 n_{k}}, B p_{2 n_{k}-1}\right) \\
& \leq \Phi\left(d\left(S p_{2 n_{k}-1}, T p_{2 n_{k}}\right)\right)
\end{aligned}
$$

By the upper semi-continuity of $\Phi(t)$, it follows that

$$
\lim _{k} A p_{2 n_{k}}=z \text {. }
$$

Using (2.5) we have

$$
d\left(A p_{2 n_{k}}, B S p_{2 n_{k}-1}\right) \leq \Phi\left(d\left(T p_{2 n_{k}}, S S p_{2 n_{k}-1}\right) .\right.
$$

Since $B, S$ are compatible and $S$ is continuous, it follows from (2.8) and Lemma 27 that

$$
d(z, S z) \leq \Phi(d(z, S z)) .
$$

This implies that $d(z, S z)=0$, i e. $z=S z$.

Since $A, T$ are compatible and $A$ and $T$ are continuous, from (2.8) and Lemma 2.7 we have

$$
A z=\lim _{k} A T p_{2 n_{k}}=T z .
$$

In view of (2.7) we have

$$
d(S z, T z) \leq \Phi(d(S z, T z))
$$

and so

$$
z=S z=T z=A z
$$

Besides, from (2.5) we have

$$
d(A z, B z) \leq \Phi(d(S z, T z))=\Phi(0)=0 .
$$

Hence

$$
z=T z=S z=A z=B z .
$$

Finally, if $T v=S v=A v=B v$, then

$$
d(T v, S z)=d(A v, B z) \leq \Phi(d(S z, T v))
$$

and so $T v=S z=T z$.

This completes the proof of Theorem 28 .

As an immediate consequence we can obtain the following result.

THEOREM 2.9. Let $(X, d)$ be a complete convex metric space, $K$ a nonempty closed subset of $X$, and $S$ and $T$ continuous mappings from $X$ into $X$ such that $\partial K \subset S(K) \cap T(K)$. Suppose that for every $n \in \mathbb{N}, A_{n}: K \rightarrow X$ is a continuous mapping with $A_{2 n}(K) \cap K \subset T(K)$ and $A_{2 n-1}(K) \cap K \subset S(K)$, and that the pairs of mappings $A_{2 n-1}, T$ and $A_{2 n}, S$ are compatible such that for any $n \in \mathbb{N}$

$$
d\left(A_{n} x, A_{n+1} y\right) \leq \Phi(d(T x, S y)), \forall x, y \in K,
$$

where $\Phi(t)$ is the same as in Theorem 2.8

If for every $n \in \mathbb{N}$ and $x \in K$,

$$
T x \in \partial K \text { implies } A_{n} x \in K \text { and } S x \in \partial K \text { implies } A_{n} x \in K \text {, }
$$

then there exists a $z \in K$ such that

$$
z=T z=S z=A_{n} z, \quad \forall n \in \mathbb{N},
$$

and if $T v=S v=A_{n} v$ for every $n \in \mathbb{N}$, then $T z=T v$.

REMARK 2.10. Theorem 2.9 is a generalization of Theorem 1 in [11] 


\section{APPLICATIONS}

Throughout this section we assume that $X$ and $Y$ are Banach spaces, $S \subset X$ is a state space, $D \subset Y$ a decision space and $\mathbb{R}=(-\infty,+\infty)$ We denote by $B(S)$ the set of all bounded real-valued functions defined on $S$.

As suggested in Bellman and Lee [18], the basic form of the functional equations of dynamic programming is

$$
f(x)=\text { opt }_{y} H(x, y, f(T(x, y)))
$$

where $x$ and $y$ represent the state and decision vectors respectively, $T$ represents the transformation of the process, and $f(x)$ represents the optimal return function with initial state $x$ (here opt denotes max or $\min$ )

In this section, we shall study the existence and uniqueness of a common solution of the following functional equations arising in dynamic programmings

$$
\begin{array}{ll}
f(x)=\sup _{y \in D} H_{1}(x, y, f(T(x, y))), & x \in S, \\
g(x)=\sup _{y \in D} H_{2}(x, y, g(T(x, y))), & x \in S, \\
p(x)=\sup _{y \in D} F_{1}(x, y, p(T(x, y))), & x \in S, \\
q(x)=\sup _{y \in D} F_{2}(x, y, q(T(x, y))), & x \in S,
\end{array}
$$

where $T: S \times D \rightarrow S, H_{2}$ and $F_{\imath}: S \times D \times \mathbb{R} \rightarrow \mathbb{R}, i=1,2$.

THEOREM 3.1. Suppose that the following conditions are satisfied

(i) $H_{\imath}$ and $F_{\imath}$ are bounded, $i=1,2$.

(ii) $\left|H_{1}(x, y, h(t))-H_{2}(x, y, k(t))\right| \leq \Phi\left(\max \left\{\left|T_{1} h(t)-T_{2} k(t)\right|\right.\right.$,

$\left.\left.\left|T_{1} h(t)-A_{1} h(t)\right|,\left|T_{2} k(t)-A_{2} k(t)\right|, \frac{1}{2}\left[\left|T_{1} h(t)-A_{2} k(t)\right|+\left|T_{2} k(t)-A_{1} h(t)\right|\right\}\right\}\right)$,

for all $(x, y) \in S \times D, h, k \in B(S)$ and $t \in S$, where $\Phi$ is the same as in Theorem 23 , and the mappings $A_{2}$ and $T_{\imath}$ are defined as follows

$$
\begin{aligned}
& A_{\imath} h(x)=\sup _{y \in D} H_{\imath}(x, y, h(T(x, y))), \quad x \in S, \quad h \in B(S) \text { and } \\
& T_{\imath} k(x)=\sup _{y \in D} F_{\imath}(x, y, k(T(x, y))), \quad x \in S, \quad k \in B(S), \cdot i=1,2 .
\end{aligned}
$$

(iii) For any $\left\{k_{n}\right\} \subset B(S)$ and $k \in B(S)$,

$$
\limsup _{n}\left|k_{n}(x)-k(x)\right|=0 \quad \text { implies } \limsup _{n}\left|T_{i \in S} k_{n}(x)-T_{i} k(x)\right|=0, \quad i=1,2 .
$$

(iv) For any $h \in B(S)$, there exist $k_{1}, k_{2} \in B(S)$ such that

$$
A_{1} h(x)=T_{2} k_{1}(x), \quad A_{2} h(x)=T_{1} k_{2}(x), \quad x \in S .
$$

(v) For any $\left\{k_{n}\right\} \subset B(S)$, if there exists $h \in B(S)$ such that

$$
\limsup _{n}\left|A_{\imath} k_{n}(x)-h(x)\right|=\limsup _{n} \sup _{x \in S}\left|T_{\imath} k_{n}(x)-h(x)\right|=0,
$$

then

$$
\limsup _{n \in S}\left|A_{i} T_{\imath} k_{n}(x)-T_{2} A_{\imath} k_{n}(x)\right|=0, \quad i=1,2 .
$$

Then the system of functional equations (3.1)-(3.4) has a unique common solution in $B(S)$. 
PROOF. For any $h, k \in B(S)$, let

$$
d(h, k)=\sup \{|h(x)-k(x)|: x \in S\},
$$

then $(B(S), d)$ is a complete metric space From (i)-(v) we know that $A_{2}$ and $T_{2}$ are self mappings of $B(S), T_{\imath}$ are continuous, $A_{1}(B(S)) \subset T_{2}(B(S)), A_{2}(B(S)) \subset T_{1}(B(S))$, and the pair of mappings $A_{2}, T_{2}$ are compatible, $i=1,2$.

Let $h_{1}, h_{2}$ be any two points of $B(S)$, let $x \in S$ and $\eta$ be any positive number, there exist $y_{1}$, and $y_{2}$ in $D$ such that

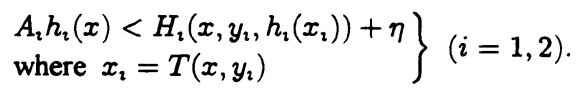

Also we have

$$
\begin{aligned}
& A_{1} h_{1}(x) \geq H_{1}\left(x, y_{2}, h_{1}\left(x_{2}\right)\right), \\
& A_{2} h_{2}(x) \geq H_{2}\left(x, y_{1}, h_{2}\left(x_{1}\right)\right) .
\end{aligned}
$$

From (3.5), (3 7) and (ii) we have

$$
\begin{aligned}
A_{1} h_{1}(x)-A_{2} h_{2}(x)< & H_{1}\left(x, y_{1}, h_{1}\left(x_{1}\right)\right)-H_{2}\left(x, y_{1}, h_{2}\left(x_{1}\right)\right)+\eta \\
\leq & \left|H_{1}\left(x, y_{1}, h_{1}\left(x_{1}\right)\right)-H_{2}\left(x, y_{1}, h_{2}\left(x_{1}\right)\right)\right|+\eta \\
\leq & \Phi\left(\operatorname { m a x } \left\{\left|T_{1} h_{1}\left(x_{1}\right)-T_{2} h_{2}\left(x_{1}\right)\right|,\left|T_{1} h_{1}\left(x_{1}\right)-A_{1} h_{1}\left(x_{1}\right)\right|\right.\right. \\
& \left|T_{2} h_{2}\left(x_{1}\right)-A_{2} h_{2}\left(x_{1}\right)\right|, \frac{1}{2}\left[\left|T_{1} h_{1}\left(x_{1}\right)-A_{2} h_{2}\left(x_{1}\right)\right|\right. \\
& \left.\left.\left.+\left|T_{2} h_{2}\left(x_{1}\right)-A_{1} h_{1}\left(x_{1}\right)\right|\right]\right\}\right)+\eta \\
\leq & \Phi\left(\operatorname { m a x } \left\{d\left(T_{1} h_{1}, T_{2} h_{2}\right), d\left(T_{1} h_{1}, A_{1} h_{1}\right),\right.\right. \\
& d\left(T_{2} h_{2}, A_{2} h_{2}\right), \frac{1}{2}\left[d\left(T_{1} h_{1}, A_{2} h_{2}\right)\right. \\
& \left.\left.\left.+d\left(T_{2} h_{2}, A_{1} h_{1}\right)\right]\right\}\right)+\eta .
\end{aligned}
$$

Similarly from (3.5), (3.6) and (ii) we have

$$
\begin{aligned}
A_{1} h_{1}(x)-A_{2} h_{2}(x) \geq & -\Phi\left(\operatorname { m a x } \left\{d\left(T_{1} h_{1}, T_{2} h_{2}\right), d\left(T_{1} h_{1}, A_{1} h_{1}\right),\right.\right. \\
& d\left(T_{2} h_{2}, A_{2} h_{2}\right), \frac{1}{2}\left[d\left(T_{1} h_{1}, A_{2} h_{2}\right)\right. \\
& \left.\left.\left.+d\left(T_{2} h_{2}, A_{1} h_{1}\right)\right]\right\}\right)-\eta .
\end{aligned}
$$

Hence we have

$$
\begin{aligned}
\left|A_{1} h_{1}(x)-A_{2} h_{2}(x)\right| \leq & \Phi\left(\operatorname { m a x } \left\{d\left(T_{1} h_{1}, T_{2} h_{2}\right), d\left(T_{1} h_{1}, A_{1} h_{1}\right),\right.\right. \\
& d\left(T_{2} h_{2}, A_{2} h_{2}\right), \frac{1}{2}\left[d\left(T_{1} h_{1}, A_{2} h_{2}\right)\right. \\
& \left.\left.\left.+d\left(T_{2} h_{2}, A_{1} h_{1}\right)\right]\right\}\right)+\eta
\end{aligned}
$$

Since (3.8) is true for any $x \in S$ and $\eta$ is any positive number, we have

$$
\begin{aligned}
d\left(A_{1} h_{1}, A_{2} h_{2}\right) \leq & \Phi\left(\operatorname { m a x } \left\{d\left(T_{1} h_{1}, T_{2} h_{2}\right), d\left(T_{1} h_{1}, A_{1} h_{1}\right),\right.\right. \\
& d\left(T_{2} h_{2}, A_{2} h_{2}\right), \frac{1}{2}\left[d\left(T_{1} h_{1}, A_{2} h_{2}\right),\right. \\
& \left.\left.\left.+d\left(T_{2} h_{2}, A_{1} h_{1}\right)\right]\right\}\right) .
\end{aligned}
$$

Therefore by Theorem 2.3, $A_{1}, A_{2}, T_{1}$ and $T_{2}$ have a unique common fixed point $h^{*} \in B(S)$, i.e $h^{*}(x)$ is a unique common solution of functional equations (3.1) - (3.4). This completes the proof.

The following result is an immediate consequence of Theorem 2.3 and Theorem 31

THEOREM 3.2. Suppose that the following conditions are satisfied:

(i) $H_{i}$ is bounded, $i=1,2$;

(ii) $\left|H_{1}(x, y, h(t))-H_{2}(x, y, k(t))\right| \leq \Phi\left(\max \left\{|h(t)-k(t)|,\left|h(t)-A_{1} h(t)\right|\right.\right.$, $\left.\left.\left|k(t)-A_{2} k(t)\right|, \frac{1}{2}\left[\left|h(t)-A_{2} k(t)\right|+\left|k(t)-A_{1} h(t)\right|\right\}\right\}\right)$ 
for all $(x, y) \in S \times D, h, k \in B(S)$ and $t \in S$, where $\Phi$ is the same as in Theorem 23 and $A_{\imath}$ is defined by

$$
A_{\imath} h(x)=\sup _{y \in D} H_{\imath}(x, y, h(T(x, y))), \quad x \in S, \quad h \in B(S), \quad i=1,2 .
$$

Then the functional equations (3.1) and (3.2) have a unique common solution in $B(S)$

REMARK 3.3. Theorem 3.2 is a generalization of Theorem 2.1 in [15]

THEOREM 3.4. Suppose that the following conditions are satisfied.

(i) $H_{\imath}$ and $F_{\imath}$ are bounded, $i=1,2$,

(ii) $\left|H_{1}(x, y, h(t))-H_{2}(x, y, k(t))\right| \leq \Phi\left(\left|T_{1} h(t)-T_{2} k(t)\right|\right)$ for all $(x, y) \in S \times D, h, k \in B(S)$ and $t \in S$, where $\Phi$ is the same as in Theorem 2.8 and $T_{2}$ is defined as in Theorem $31, i=1,2$;

(iii) For any $\left\{k_{n}\right\} \subset B(S)$ and $k \in B(S)$,

$$
\limsup _{n} \sup _{x \in S}\left|k_{n}(x)-k(x)\right|=0 \text { implies } \limsup _{n}\left|T_{i \in S} k_{n}(x)-T_{\imath} k(x)\right|=0
$$

and

$$
\lim _{n} \sup _{x \in S}\left|A_{2} k_{n}(x)-A_{2} k(x)\right|=0, \quad i=1,2,
$$

where $A_{\imath}$ is defined as in Theorem $3.1, i=1,2$;

(iv) For any $h \in B(S)$ such that $\sup _{x \in S}|h(x)|=1$, there exist $k_{1}, k_{2} \in B(S)$ such that

$$
\sup _{x \in S}\left|k_{2}(x)\right| \leq 1 \quad \text { and } \quad T_{\imath} k_{\imath}(x)=h(x), \quad x \in S, \quad i=1,2 ;
$$

(v) For any $h \in B(S)$ such that $\sup _{x \in S}|h(x)| \leq 1$, there exist $k_{1}, k_{2} \in B(S)$ such that $\sup _{x \in S}\left|k_{2}(x)\right| \leq 1, \quad i=1,2, \quad A_{1} h(x)=T_{2} k_{1}(x) \quad$ and $\quad A_{2} h(x)=T_{1} k_{2}(x), \quad x \in S ;$

(vi) For any $h \in B(S)$ such that $\sup _{x \in S}|h(x)| \leq 1$,

$$
\sup _{x \in S}\left|T_{\imath} h(x)\right|=1 \quad \text { implies } \sup _{x \in S}\left|A_{j} h(x)\right| \leq 1, \quad i, j=1,2 ;
$$

(vii) For any $\left\{k_{n}\right\} \subset B(S)$, if there exists $h \in B(S)$ such that $\sup _{x \in S}\left|T_{i} k_{n}(x)\right| \leq 1$ and

$$
\limsup _{n}\left|A_{\imath} k_{n}(x)-h(x)\right|=\limsup _{n}\left|T_{\imath \in S} k_{n}(x)-h(x)\right|=0,
$$

then

$$
\limsup _{n \in S}\left|A_{\imath} T_{\imath} k_{n}(x)-T_{2} A_{2} k_{n}(x)\right|=0, \quad i=1,2
$$

Then the system of functional equations (3 1) - (3.4) have a unique common solution $h^{*} \in B(S)$ and $\sup _{x \in S}\left|h^{*}(x)\right| \leq 1$.

PROOF. Let us consider $B(S)$ as a Banach space of all bounded real-valued functions defined on $S$ with a supremum norm, and $K$ the closed unit ball in $B(S)$. By conditions (i)-(vii) we know that $A_{\imath}: K \rightarrow B(S)$ and $T_{\imath}: B(S) \rightarrow B(S), i=1,2$, satisfy all of the conditions of Theorem 2.8 and have a unique common fixed point $h^{*} \in K$, i.e, $h^{*}(x)$ is a unique common solution of functional equations (3.1) - (3 4).

REMARK 3.5. Theorem 34 is a generalization of Theorem 3.2 in [14].

ACKNOWLEDGMENT. The authors are indebted to the referees for their helpful comments The second author was supported by NON DIRECTED RESEARCH FUND, Korea Research Foundation 


\section{REFERENCES}

[1] JUNGCK, G., Compatible mappings and common fixed points, Internat. J. Math. \& Math. Scl. 9 (1986), 771-779.

[2] JUNGCK, G., Common fixed points for compatible maps on the unit interval, Proc. Amer. Math. Soc. 115 (1992), 495-499

[3] JUNGCK, G., Common fixed points for commuting and compatible maps on compacta, Proc. Amer. Math. Soc. 103 (1988), 977-983

[4] JUNGCK, G., Compatible mappings and common fixed points (2), Internat. J. Math. \& Math. Scl. 11 (1988), 285-288

[5] JUNGCK, G, MURTHY, P.P and CHO, Y.J., Compatible mappings of type (A) and common fixed points, Math. Japonica 38 (1993), 381-390.

[6] JUNGCK, G. and RHOADES, B.E., Some fixed point theorems for compatible maps, Internat. $J$. Math. \& Math. Sci. 16 (1993), 417-428.

[7] KANG, S.M., CHO, Y.J and JUNGCK, G, Common fixed points of compatible mappings, Internat. J. Math. \& Math. Scl. 13 (1990), 61-65

[8] KANG, S.M. and PYU, JW., A common fixed point theorem for compatible mappings, Math. Japonica 35 (1990), 153-157.

[9] MURTHY, P.P., CHANG, S S., CHO, Y.J and SHARMA, B.K., Compatible mappings of type (A) and common fixed point theorems, Kyungpook Math. J. 32 (1992), 203-216.

[10] CHANG, S.S., On common fixed point theorem for a family of $\Phi$-contraction mappings, Math. Japonica 29 (1984), 527-536.

[11] HADZIC, O, On coincidence theorems for a family of mappings in convex metric spaces, Internat. J. Math. \& Math. Sci. 10 (1987), 453-460.

[12] HADZIC, O., Common fixed point theorems for a family of mappings in complete metric spaces, Math. Japonica 29 (1984), 127-134

[13] SINGH, S.L. and SINGH, S.P., A fixed point theorem, Indian J. Pure Appl. Math. 11 (1980), 1584-1586.

[14] BASKARAN, R and SUBRAHMANYAM, P.V., A note on the solution of a class functional equation, Applicable Anal. 22 (1986), 235-241.

[15] BHAKTA, P.C. and MITRA, S., Some existence theorems for functional equations arising in dynamic programming, J. Math. Anal. Appl. 98 (1984), 348-362.

[16] JACHVMSKI, J., Common fixed point theorems for some families of maps, Indian J. Pure Appl. Math. 25 (9) (1994), 927-937.

[17] ASSAD, N.A. and KIRK, W A., Fixed point theorems for set-valued mappings of contractive type, Pacific J. Math. 43 (1972), 553-562.

[18] BELLMAN, R. and LEE, E.S., Functional equations arising in dynamic programming, Aequationes Math. 17 (1978), 1-18. 


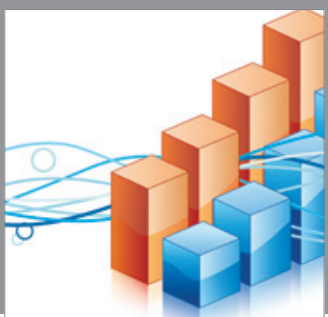

Advances in

Operations Research

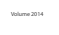

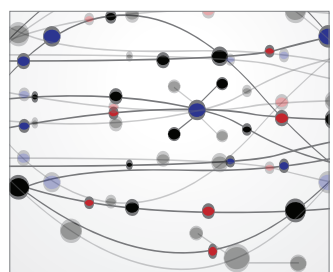

\section{The Scientific} World Journal
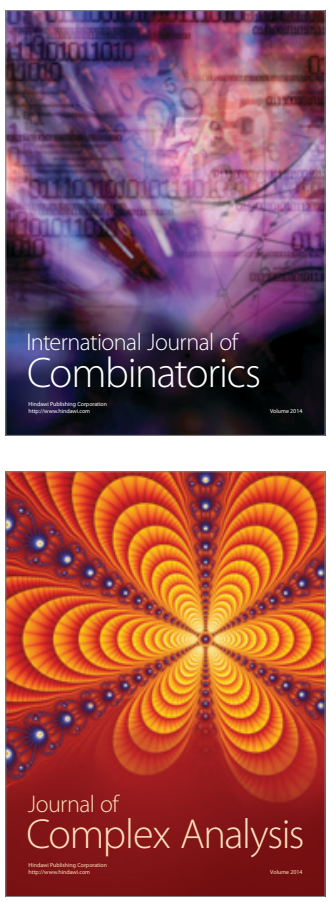

International Journal of

Mathematics and

Mathematical

Sciences
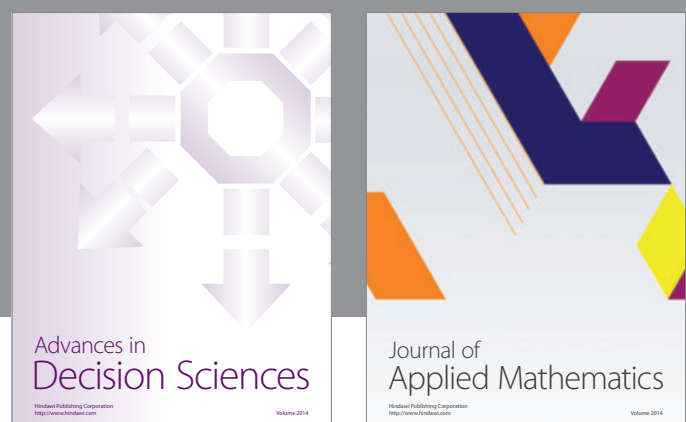

Journal of

Applied Mathematics
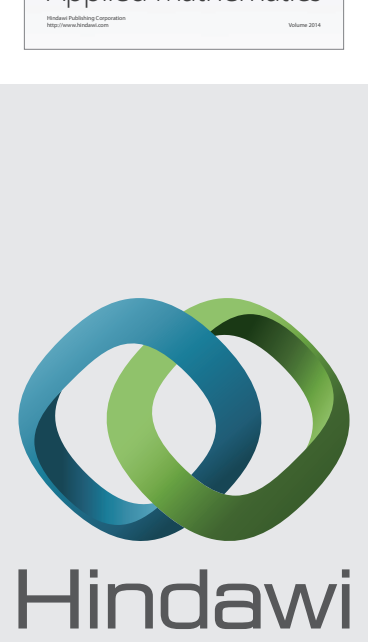

Submit your manuscripts at http://www.hindawi.com
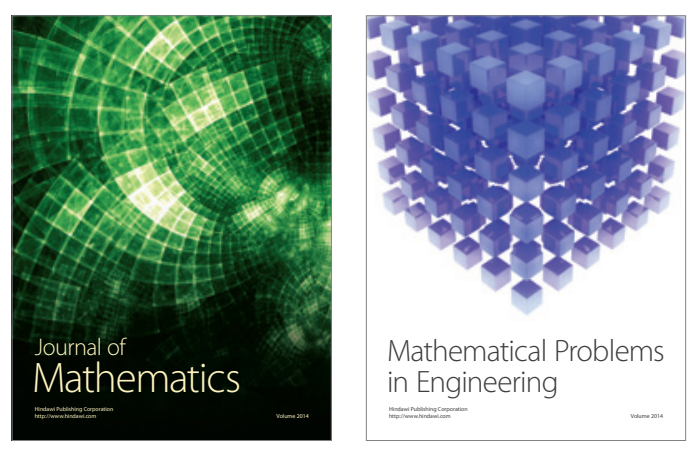

Mathematical Problems in Engineering
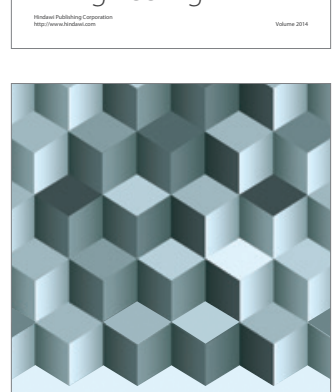

Journal of

Function Spaces
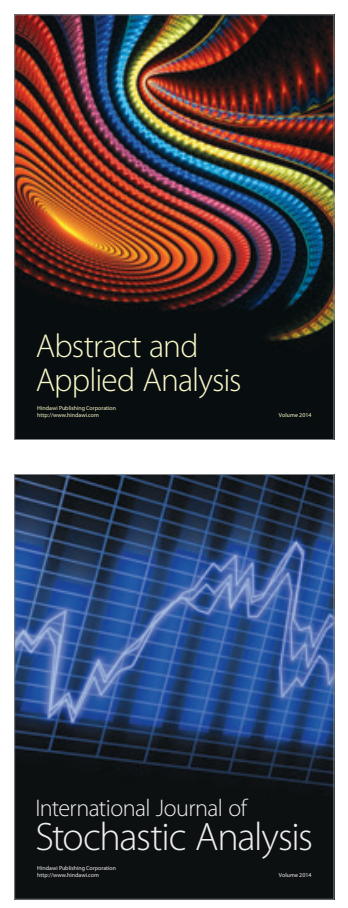

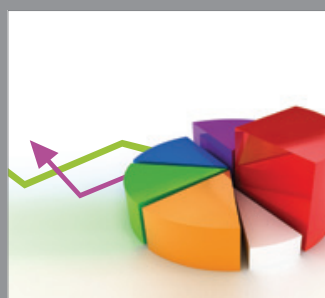

ournal of

Probability and Statistics

Promensencen
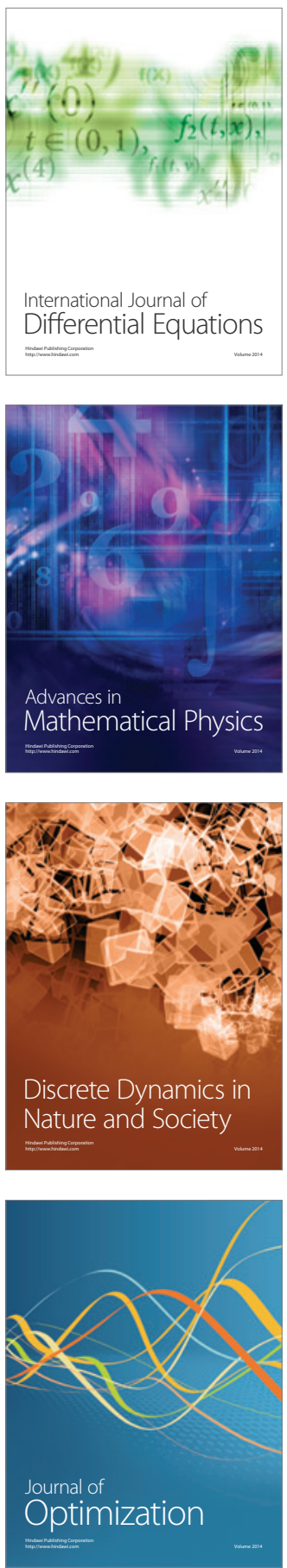